\title{
COMPETTTION BETWEEN THE REARRANGEMENT OF ELECTRODEPOSITED OVERLAYERS OF COPPER ON PLATINUM AND THE HYDROGEN ELECTRODE REACTIONS *
}

\author{
D. MARGHERITIS, R.C. SALVAREZZA, M.C. GIORDANO and A.J. ARVIA \\ Instituto de Investigaciones Fisicoquimicas Teóricas y Aplicadas, INIFTA **, Casilla de Correo 16 , \\ Sucursal 4, (1900) La Plata (Argentina)
}

(Received 13th January 1987)

\begin{abstract}
The electrodeposition of $\mathrm{Cu}^{2+}$ ions on polycrystalline $\mathrm{Pt}$ from acid aqueous $\mathrm{CuSO}_{4}$ solutions was studied in the underpotential (upd) and overpotential (opd) ranges by using potentiostatic and potentiodynamic techniques. In the upd region, monotonic current transients were recorded for potentials $\left(E_{\mathrm{d}}\right)$ more positive than the reversible potential $\left(E_{\mathrm{r}}\right)$ of the $\mathrm{Cu}^{2+} / \mathrm{Cu}$ electrode. For $\mathrm{Cu}$ electrodeposits involving a charge density close to that of the complete $\mathrm{Cu}$ monolayer, the hydrogen electrode reactions were strongly inhibited. Otherwise, non-monotonic current transients were recorded for $E_{\mathrm{d}} \rightarrow E_{\mathrm{x}}$. These transients suggest rearrangement of the monolayer structure when additional $\mathrm{Cu}$ atoms are deposited. In the opd region where the early stages of three-dimensional (3D) nucleation and growth take place, the contribution of the hydrogen electrode reaction reappeared due to bare platinum sites which are present in the early stages of 3D growth. The present results in the limiting case can be interpreted in terms of a $2 \mathrm{D}$ to $3 \mathrm{D}$ transition at the overlayer level implying a certain distribution of clusters and the reappearance of the bare substrate surface. This process, in principle, accounts for the anomalies observed systematically in voltammetric measurements for this system.
\end{abstract}

\section{INTRODUCTION}

The underpotential deposition (upd) of $\mathrm{Cu}$ on polycrystalline $(\mathrm{pc})$ and singlecrystal Pt electrodes has been studied extensively [1-5]. The adsorption of $\mathrm{Cu}$ can cause inhibition of the $\mathrm{H}$-atom adsorption-desorption processes on $\mathrm{Pt}$ [6]. Repulsive interactions between $\mathrm{Cu}$ and $\mathrm{H}$ atoms have been reported at potentials more negative than the potential of the $\mathrm{Cu}^{2+} / \mathrm{Cu}$ reversible electrode $\left(E_{\mathrm{r}}\right)$, although

\footnotetext{
* In honour of Professor H. Gerischer on the occasion of his retirement as Director of the Fritz-Haber Institute.

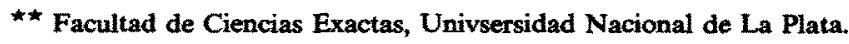

0022-0728/87/\$03.50 1987 Elsevier Sequoia S.A.
} 
attractive interactions seem to operate at sufficiently large negative potential values [7]. The fact that $\mathrm{H}$-atom adsorption is completely suppressed when one monolayer of $\mathrm{Cu}$ is deposited was taken as proof that upd $\mathrm{Cu}$ is uniformly distributed on the $\mathrm{Pt}$ surface [8]. Otherwise, no marked differences were observed between non-equilibrium and equilibrium conditions for the deposition of the first $\mathrm{Cu}$ monolayer [9]. Despite these facts, at present it is not sufficiently clear whether the deposition of the second layer of $\mathrm{Cu}$ atoms begins either before [10] or after [2] completion of the first monolayer. Likewise, according to the coverage by upd atoms, a marked change in the kinetics of bulk metal growth can be observed [8,11], and in this respect the electroformation of thin $\mathrm{Cu}$ patches at a potential close to $E_{\mathrm{r}}$ was also reported [12].

The present work refers to the competition between both the upd and the early stages of $\mathrm{Cu}$ overpotential deposition on $\mathrm{pc} \mathrm{Pt}$ and polyfacetted single-crystal (pfsc) $\mathrm{Pt}$ and the hydrogen electrode reaction (HER) proceeding on a bare $\mathrm{Pt}$ surface. The results can be interpreted through possible structural changes of the first $\mathrm{Cu}$ layers depending on the time and potential windows of voltammetric and potentiostatic experiments.

\section{EXPERIMENTAL}

$\mathrm{Cu}$ electrodeposition was done on pc $\mathrm{Pt}$ and pfsc spherical Pt [13] working electrodes covering the range from $\mathrm{Cu}$ submonolayers up to the early stages of bulk $\mathrm{Cu}$ electrodeposits. The pretreatment of the working electrodes was similar to that reported in ref. 14, and the evaluation of their real areas, of the order of $0.2 \mathrm{~cm}^{2}$, was done using the $\mathrm{H}$-adatom voltammetric charge at $0.1 \mathrm{~V} / \mathrm{s}$ in $0.5 \mathrm{M} \mathrm{H}_{2} \mathrm{SO}_{4}$, by taking $210 \mu \mathrm{C} / \mathrm{cm}^{2}$ to be the $\mathrm{H}$-adatom monolayer charge. The potential of the working electrode was measured against a reversible hydrogen reference electrode (RHE) in $0.5 \mathrm{M} \mathrm{H}_{2} \mathrm{SO}_{4}$. A large-area $\mathrm{Pt}$ sheet was used as the counter-electrode. The three-electrode system was placed in a conventional three-compartment electrochemical cell. Electrochemical experiments were run at $30 \pm 0.1^{\circ} \mathrm{C}$ in $\times M \mathrm{CuSO}_{4}+$ $0.5 \mathrm{M} \mathrm{H}_{2} \mathrm{SO}_{4}\left(5 \times 10^{-5}<x<5 \times 10^{-3}\right)$. Solutions were prepared from A.R. chemicals and triply distilled water free of impurities, as followed through the repetitive voltammetric response in the $\mathrm{H}$-adatom potential range [15]. Single and repetitive triangular potential voltammograms and potentiostatic current transients were recorded by employing the electronic devices referred to in ref. 14 .

\section{RESULTS}

Repetitive stabilized voltammograms for pc Pt at $0.005 \mathrm{~V} / \mathrm{s}$ between $E_{\mathrm{s}, \mathrm{a}}=1.05$ $\mathrm{V}$ and $E_{\mathrm{s}, \mathrm{c}}=0.17 \mathrm{~V}$ in $1 \times 10^{-3} M \mathrm{CuSO}_{4}+0.5 \mathrm{M} \mathrm{H}_{2} \mathrm{SO}_{4}$ (Fig. 1) show in the negative potential scan a peak at $0.85 \mathrm{~V}$ which corresponds to the electrodesorption of $\mathrm{O}$ species from the $\mathrm{Pt}$ substrate. In the range $0.75-0.40 \mathrm{~V}$, the broad and complex current peak implies at least three main contributions, namely, a hump at $0.68 \mathrm{~V}$ $\left(\mathrm{I}_{\mathrm{c}}\right)$, a peak at $0.6 \mathrm{~V}\left(\mathrm{II}_{\mathrm{c}}\right)$ and a poorly defined peak at $0.42\left(\mathrm{III}_{\mathrm{c}}\right)$. The broad peak is followed by a small peak at $0.35 \mathrm{~V}\left(\mathrm{IV}_{\mathrm{c}}\right)$ and a hump $\left(\mathrm{V}_{\mathrm{c}}\right)$ at $0.25 \mathrm{~V}$. At more 
negative potentials, a current peak $\left(\mathrm{VI}_{\mathrm{c}}\right)$ can also be observed. The subsequent electrooxidation scan presents a large peak at $0.25 \mathrm{~V}\left(\mathrm{VI}_{\mathrm{a}}\right)$ followed by a hump $\left(\mathrm{V}_{\mathrm{a}}\right)$, a well-defined peak $\left(\mathrm{IV}_{\mathrm{a}}\right)$ at $0.37 \mathrm{~V}$ and a broad and complex current peak extending between 0.45 and $0.8 \mathrm{~V}$. The latter involves a peak at $0.52 \mathrm{~V}$ ( (III $_{\mathrm{a}}$ ), another one at $0.67 \mathrm{~V}\left(\mathrm{II}_{\mathrm{a}}\right)$ and a hump at $0.72 \mathrm{~V}\left(\mathrm{I}_{\mathrm{a}}\right)$. Likewise, at potentials exceeding $0.85 \mathrm{~V}$, the current increases due to $\mathrm{O}$ electroadsorption. According to earlier reported data [10], the conjugated pair of peaks $\mathrm{I}_{c} / \mathrm{I}_{\mathrm{a}}, \mathrm{II}_{\mathrm{c}} / \mathrm{II}_{\mathrm{a}}$ and $\mathrm{III}_{\mathrm{c}} / \mathrm{III}_{\mathrm{a}}$ are associated with the upd and anodic stripping of strongly bounded $\mathrm{Cu}$, whereas the pair of peaks $I V_{c} / I V_{a}$ and $V_{c} / V_{a}$ are related to the upd and anodic stripping of weakly and very weakly bound $\mathrm{Cu}$, respectively. Finally, as the applied potential tends to $E_{\mathrm{r}}=0.25 \mathrm{~V}$ for $10^{-3} M \mathrm{Cu}^{2+}$, the pair of peaks $\mathrm{VI}_{\mathrm{c}} / \mathrm{VI}_{\mathrm{a}}$ corresponding to the electrodeposition and electrodissolution of bulk $\mathrm{Cu}$ can be observed. A more detailed voltammogram run at a low sweep rate for upd $\mathrm{Cu}$ is also presented in Fig. 1.

The influence of the degree of surface coverage by $\mathrm{Cu}$ atoms on the HER can be followed through voltammograms run at $0.025 \mathrm{~V} / \mathrm{s}$ in $5 \times 10^{-3} \mathrm{M} \mathrm{CuSO}_{4}$ between $E_{\mathrm{s}, \mathrm{a}}=1.35 \mathrm{~V}$ and an $E_{\mathrm{s}, \mathrm{c}}$ value which is changed progressively from 0.10 to $-0.10 \mathrm{~V}$ (Fig. 2). The voltammetric charge related to $H$ electrooxidation becomes more important as $E_{\mathrm{s}, \mathrm{c}}$ is shifted in the negative direction, but the cathodic charge
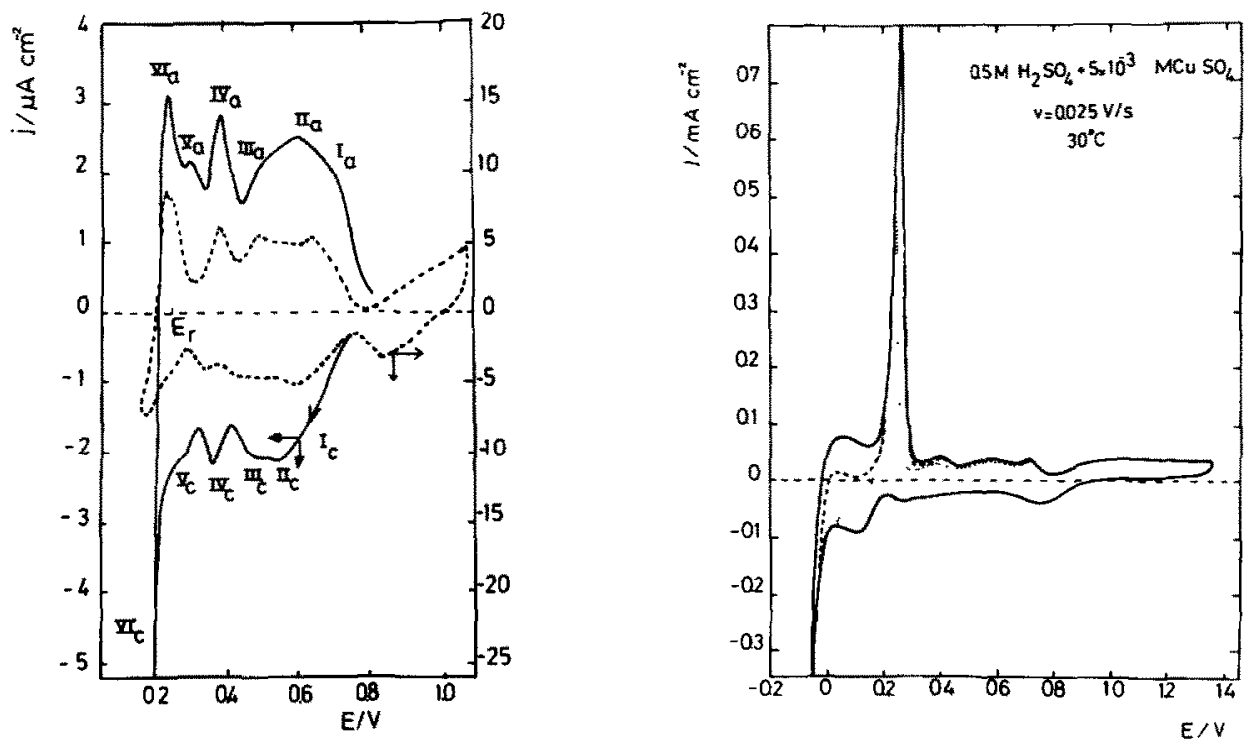

Fig. 1. $j / E$ profile for a pc Pt electrode at $v=0.005 \mathrm{~V} / \mathrm{s}$ between $E_{s, \mathrm{a}}=1.05 \mathrm{~V}$ and $E_{\mathrm{s}, \mathrm{c}}=0.17 \mathrm{~V}$ $(--)$ and at $v=0.0025 \mathrm{~V} / \mathrm{s}$ between $E_{\mathrm{s}, \mathrm{a}}=0.85 \mathrm{~V}$ and $E_{\mathrm{s}, \mathrm{c}}=0.2 \mathrm{~V}\left(\longrightarrow\right.$ ) in $1 \times 10^{-3} \mathrm{M}$ $\mathrm{CuSO}_{4}+0.5 \mathrm{M} \mathrm{H}_{2} \mathrm{SO}_{4} \cdot \mathrm{T}=30^{\circ} \mathrm{C}$.

Fig. 2. $j / E$ profile for a pc Pt electrode at $v=0.025 \mathrm{~V} / \mathrm{s}$ between $E_{\mathrm{s}, \mathrm{a}}=1.35 \mathrm{~V}$ and $E_{\mathrm{s}, \mathrm{c}}$ changed stepwise in the negative direction in $5 \times 10^{-3} \mathrm{M} \mathrm{CuSO}_{4}+0.5 \mathrm{M} \mathrm{H}_{2} \mathrm{SO}_{4} . T=30^{\circ} \mathrm{C}$. 
resulting from integration between 0.70 and $0 \mathrm{~V}$, which is unambiguously related to $\mathrm{Cu}$ electrodeposition, becomes nearly constant and close to $0.80 \mathrm{mC} / \mathrm{cm}^{2}$. This charge value is consistent with that required for nearly two complete monolayers of $\mathrm{Cu}$ atoms. It is surprising that even under these circumstances a large amount of hydrogen electrooxidation charge can be detected voltammetrically during the positive scan. In principle, this result can be easily understood for a bare or partially covered Pt surface, but it is unexpected for an electrode surface which presumably would be completely covered by $\mathrm{Cu}$ layers. Therefore, these results suggest that bare $\mathrm{Pt}$ sites exist even for $\mathrm{Cu}$ electrodeposit charges exceeding the monolayer charge. Similar experiments carried out with a pfsc Pt electrode led to the same results. This indicates that the HER current cannot be attributed either to grain boundaries or to defects present in pc Pt.

Voltammograms of $\mathrm{Cu}$ electrodeposits formed in $1 \times 10^{-3} M \mathrm{CuSO}_{4}+0.5 \mathrm{M}$ $\mathrm{H}_{2} \mathrm{SO}_{4}$ by holding the electrode potential at different values of $E_{\mathrm{d}}\left(-0.1<E_{\mathrm{d}}<1.1\right.$ $\mathrm{V}$ ), for $60 \mathrm{~s}$ were recorded immediately after their formation by applying a potential ramp at $10 \mathrm{~V} / \mathrm{s}$ down to $E_{\mathrm{s}, \mathrm{c}}=-0.1 \mathrm{~V}$, and finally for the anodic stripping at 0.1 $\mathrm{V} / \mathrm{s}$ from $E_{\mathrm{s}, \mathrm{c}}$ upwards. When $E_{\mathrm{d}}$ was held in the O-electroadsorption potential range where the $\mathrm{Pt}$ surface is free of electrodeposited $\mathrm{Cu}$, the stripping profile showed a peak at $0.02 \mathrm{~V}$ which corresponds to the electrooxidation of molecular hydrogen. The peaks related to the electrooxidation of weakly and strongly bounded $\mathrm{H}$ adatoms, at 0.13 and $0.25 \mathrm{~V}$, respectively, were also observed as broad contributions mounted on the corresponding baseline, presumably related to residual molecular hydrogen electrooxidation (Figs. $3 \mathrm{a}$ and $3 \mathrm{~b}$ ). The overall voltammetric charge density, related to $\mathrm{H}$ electrooxidation, $q_{\mathrm{H}}$, is roughly estimated as 0.4

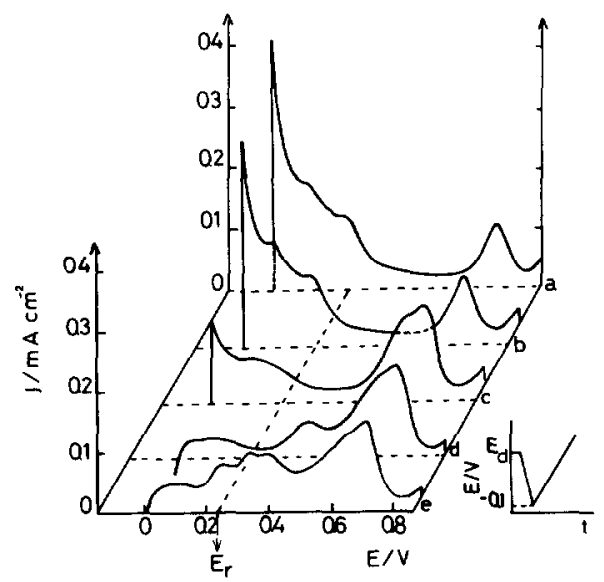

Fig. 3. $j / E$ profile obtained for a pc Pt electrode at $v=0.1 \mathrm{~V} / \mathrm{s}$ in $1 \times 10^{-3} M \mathrm{CuSO}_{4}$ after applying the following potential programme. The $\mathrm{Cu}$ electrodeposit was made at different values of $E_{\mathrm{d}}$ as indicated below, for $t_{\mathrm{d}}=60 \mathrm{~s}\left(E_{\mathrm{d}}>E_{\mathrm{r}}\right)$, then potential ramped at $10 \mathrm{~V} / \mathrm{s}$ to $-0.10 \mathrm{~V}$ and finally, the $j / E$ profile was recorded. $T=30^{\circ} \mathrm{C}$. $E_{\mathrm{d}} / \mathrm{V}$ : (a) 1.1 ; (b) 0.80 ; (c) 0.5 ; (d) 0.40 ; (e) 0.25 . 
$\mathrm{mC} / \mathrm{cm}^{2}$. The voltammograms also comprise a small amount of residual strongly bonded $\mathrm{Cu}, q_{\mathrm{Cu}}=0.075 \mathrm{mC} / \mathrm{cm}^{2}$, as detected from the peak at $0.75 \mathrm{~V}\left(\mathrm{I}_{\mathrm{a}}\right)$, which is probably due to some minor readsorption taking place during the stripping scan.

On the other hand, when $E_{\mathrm{d}}$ was held in the upd region $\left(0.80<E_{\mathrm{d}}<0.25 \mathrm{~V}\right)$ the contribution of the H-electrooxidation reactions decreased (Figs. 3c-3e). The progressive inhibition of these reactions was accompanied by the increasing development of the complex peak related to strongly bound $\mathrm{Cu}$ (Fig. 3c) [8]. Furthermore, as $E_{\mathrm{d}}$ approached $E_{\mathrm{r}}$, the formation of weakly bound $\mathrm{Cu}$ could be detected (peak $\mathrm{IV}_{\mathrm{a}}$ ). Accordingly, the electrooxidation of strongly adsorbed $\mathbf{H}$ atoms decreased (Fig. 3d) to reach a minimum value. Finally, for $E_{\mathrm{d}}=E_{\mathrm{r}}$, peaks $\mathrm{VI}_{\mathrm{a}}$ and $\mathrm{V}_{\mathrm{a}}$, which are related to bulk and very weakly bound $\mathrm{Cu}$, respectively, were observed, and in this case the $\mathrm{H}$-electrooxidation charge began to increase (Fig. 3e).

From the anodic stripping of electrodeposits done at $E_{\mathrm{d}}<E_{\mathrm{r}}$ (Fig. 4) the relative contributions of the peaks assigned to the different types of $\mathrm{Cu}$ as a function of $E_{\mathrm{d}}$ can be determined. Thus, as $E_{\mathrm{d}}$ is gradually made more negative, peaks related to weakly bound and very weakly bound $\mathrm{Cu}$ increase in relation to that of strongly bound $\mathrm{Cu}$, and simultaneously both the electrooxidation charges of molecular hydrogen and weakly adsorbed $\mathrm{H}$ atoms increase in the $0.2-0 \mathrm{~V}$ range. Furthermore, bulk $\mathrm{Cu}$ is present during the stripping scan, and the corresponding charge increases as $E_{\mathrm{d}}$ moves in the negative potential direction (Figs. 4a-4d). Both the total charge and the maximum value of current related to $H$ electrooxidation plotted vs. $E_{\mathrm{d}}$ (Fig. 5) show a minimum at $E_{\mathrm{d}} \cong E_{\mathrm{r}}$. Similar experiments carried out at $E_{\mathrm{d}}=0 \mathrm{~V}$ by increasing the deposition time from $30 \mathrm{~s}$ to $180 \mathrm{~s}$ resulted in progressive suppression of the $\mathrm{H}$-electrooxidation current.

Other types of experiment were carried out by forming the $\mathrm{Cu}$ monolayer at $E_{\mathrm{d}} \cong E_{\mathrm{r}}$ for $55 \mathrm{~s}$ under equilibrium conditions; immediately afterwards the potential was stepped to an $E_{\mathrm{s}}$ value lower than $E_{\mathrm{r}}$ for $t=5 \mathrm{~s}$, followed by a potential ramp at $10 \mathrm{~V} / \mathrm{s}$ to reach $-0.10 \mathrm{~V}$ and finally anodically stripped at $0.10 \mathrm{~V} / \mathrm{s}$ (Fig. 6). In

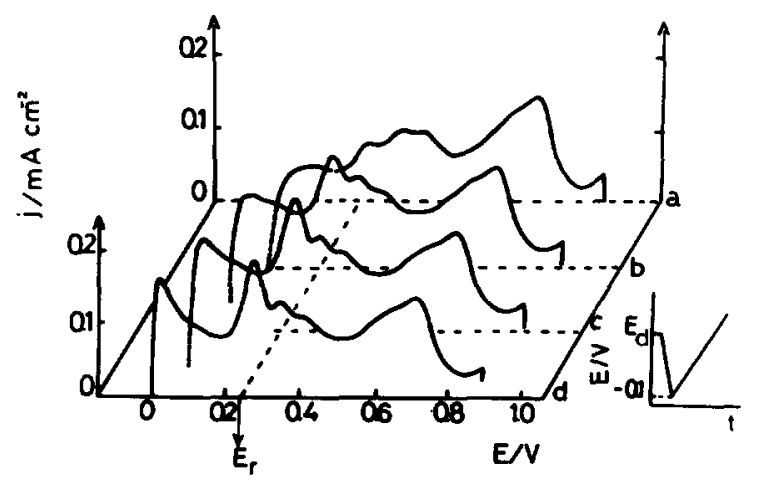

Fig. 4. $j / E$ profiles similar to those depicted in Fig. 3 recorded for the Cu electrodeposit at $E_{\mathrm{d}}<E_{\mathrm{r}}$. $T=30^{\circ} \mathrm{C}$. $E_{\mathrm{d}} / \mathrm{V}$ : (a) 0.25 ; (b) 0.15 ; (c) 0.10 ; (d) 0.05 . 


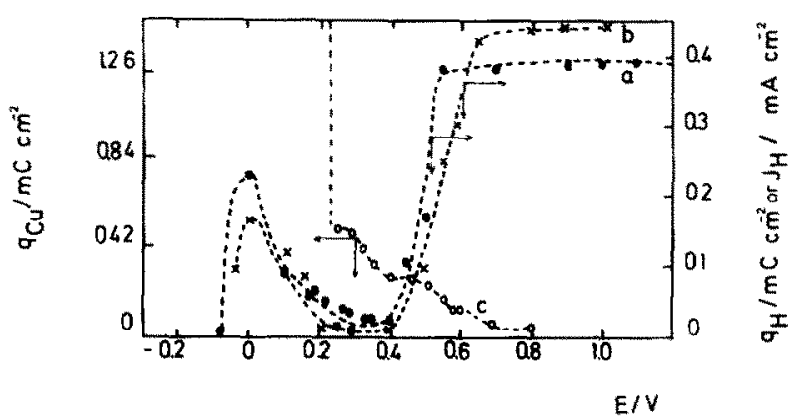

Fig. 5. (a) $q_{\mathrm{H}}$ vs. $E$ plot, (b) $J_{\mathrm{H}}$ vs. $E$ plot and (c) $q_{\mathrm{Cu}}$ vs. $E$ plot for a pe Pt electrode in $1 \times 10^{-3} M$ $\mathrm{CuSO}_{4}$.

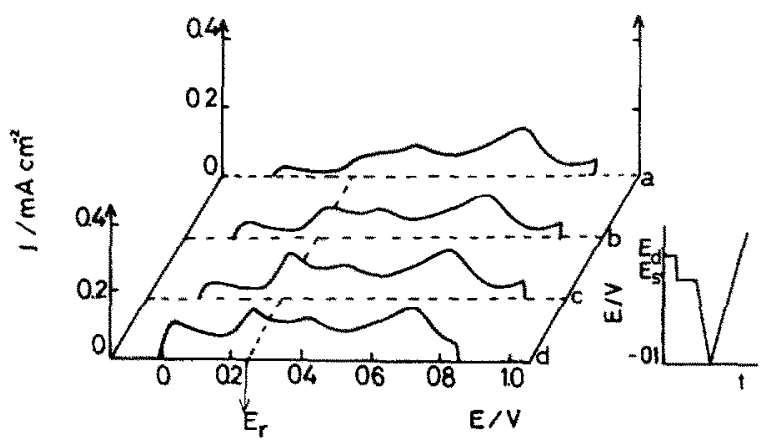

Fig. 6. $j / E$ profiles similar to those shown in Figs. 3 and 4 but including a potential step at $E_{\mathrm{s}}$ for $t_{\mathrm{s}}=5$ $s$ prior to the ramp at $10 \mathrm{~V} / \mathrm{s}$ to $-0.10 \mathrm{~V} . T=30^{\circ} \mathrm{C} . E_{\mathrm{d}}=0.28 \mathrm{~V} . E_{\mathrm{s}} / \mathrm{V}:$ (a) $0.25 ;$ (b) $0.15 ;$ (c) 0.08 ; (d) 0.05 .

this case, inclusion of the potential step at $E_{\mathrm{s}}$ resulted in an increase of the $H$-electrooxidation current, but the overall effect was smaller than that observed when the Cu electrodeposit was made directly at $E_{\mathrm{d}}<E_{\mathrm{r}}$. Certainly, the electrooxidation current became more evident as $E_{\mathrm{d}}$ was lowered. The same results were also obtained for lower $\mathrm{CuSO}_{4}$ concentrations.

\section{Current transients at constant potential}

Complementary data were obtained by running potentiostatic current transients over a wide range of applied potential steps. For these runs, the potential was first held at $E_{\mathrm{s}}=0.80 \mathrm{~V}$ for $20 \mathrm{~s}$ to remove the copper electrodeposit completely and then stepped to $E_{\mathrm{d}}\left(0.10<E_{\mathrm{d}}<0.60 \mathrm{~V}\right)$.

For $E_{\mathrm{d}}>E_{\mathrm{r}}$, only decreasing current transients can be observed (Fig. 7), but as $E_{\mathrm{d}}$ is held in the potential range of peaks $\mathrm{IV}_{\mathrm{c}}$ and $\mathrm{V}_{\mathrm{c}}$ and gradually approaches $E_{\mathrm{r}}$, the initial current decrease is followed by a current plateau, which becomes more 


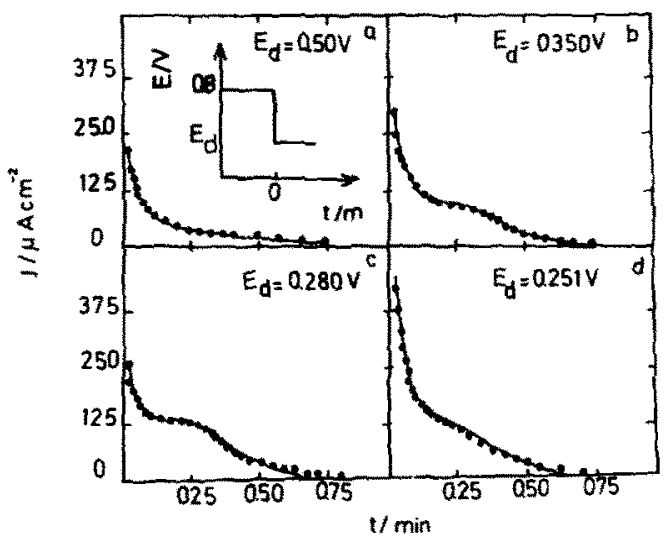

Fig. 7. Current transients at constant potential $\left(E_{\mathrm{d}}>E_{\mathrm{r}}\right)$ for a pe Pt electrode in $10^{-3} M \mathrm{CuSO}_{4}$.

pronounced as $E_{\mathrm{d}}$ becomes closer to $E_{\mathrm{r}}$. The charge density $\left(q_{\mathrm{Cu}}\right)$ resulting from the current transients for values of $E_{\mathrm{d}}$ slightly more positive than $E_{\mathrm{r}}$ becomes closer to the charge density of the $\mathrm{Cu}$ monolayer. The limiting value of $q_{\mathrm{Cu}}$ is attained for $t \cong 40 \mathrm{~s}$.

As $E_{\mathrm{d}}$ is set more negative than $E_{\mathrm{r}}$, the current transients again exhibit an initial decreasing current portion, but the latter is followed by a current increase up to a maximum value $\left(I_{M}\right)$ at the time $t_{M}$ and later by a slow decrease (Fig. 8). Moreover, as $E_{\mathrm{d}}$ moves towards more negative values, $I_{M}$ increases and $t_{M}$ decreases. Under these circumstances, the magnitude of the current transients depends strongly on the solution stirring because bulk $\mathrm{Cu}$ growth becomes diffusion-controlled. Similarly, runs including a previous step at $E_{\mathrm{s}}\left(E_{\mathrm{r}}<E_{\mathrm{s}}<0.6 \mathrm{~V}\right)$ for $t_{\mathrm{s}}=60 \mathrm{~s}$, to obtain

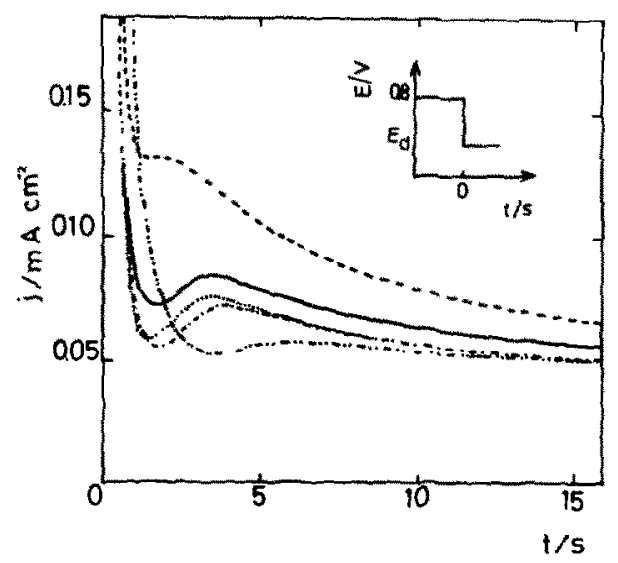

Fig. 8. Current transients at constant potential $\left(E_{\mathrm{d}}<E_{\mathrm{r}}\right)$ for a pe Pt electrode in $1 \times 10^{-3} \mathrm{M} \mathrm{CuSO}_{4}$. $\left.T=30^{\circ} \mathrm{C} .(-\cdots) ,0.115 \mathrm{~V} ;(-\cdots) 0.093 \mathrm{~V} ;(\cdots)\right) 0.043 \mathrm{~V} ;(\longrightarrow) 0.007 \mathrm{~V} ;(-\longrightarrow-)-0.008 \mathrm{~V}$. 
different coverages of upd $\mathrm{Cu}$ on $\mathrm{Pt}$, show some interesting effects. For instance, at $E_{\mathrm{d}}=0.10 \mathrm{~V}$ as $E_{\mathrm{s}}$ moves in the negative direction approaching $E_{\mathrm{r}}, I_{\mathrm{M}}$ increases and $t_{\mathrm{M}}$ decreases. These facts indicate an enhancement of bulk $\mathrm{Cu}$ growth according to the upd $\mathrm{Cu}$ coverage.

\section{DISCUSSION}

The upd of $\mathrm{Cu}$ on $\mathrm{Pt}$ has been described in terms of two different models. The first one considers the $\mathrm{Cu}-\mathrm{Pt}$ layer as a perfect non-mobile structure formed by random (gaseous) adsorption on which bulk $\mathrm{Cu}$ deposition occurs [8]. This interpretation is, in principle, supported by the absence of $\mathrm{H}$-atom electroadsorption-electrodesorption when a monolayer of $\mathrm{Cu}$ has been formed. The second model takes into account that $\mathrm{Cu}$ deposition occurs before the completion of the $\mathrm{Cu}-\mathrm{Pt}$ layer and that ageing processes of this imperfect structure result in the formation of a complete $\mathrm{Cu}-\mathrm{Pt}$ layer [10]. This approach is in agreement with the observation of $H$-adatom reactions at potentials more negative than $E_{\mathrm{r}}$ when the charge associated with $\mathrm{Cu}$ coverage exceeds that expected for the corresponding monolayer [10]. In contrast with these two extreme situations, the present results suggest that despite the distinctive characteristic of these kinetic and structural models one or the other can be applicable, depending on the potential and time windows of the voltammetric and potentiostatic experiments. Thus, when the $\mathrm{Cu}$ monolayer is formed close to the equilibrium potential $\left(E_{\mathrm{d}} \cong E_{\mathrm{r}}\right)$, a perfect $2 \mathrm{D}$ structure can be attained and in this case $\mathrm{Cu}$ atoms become uniformly distributed over the Pt surface. This fact is consistent with the absence of voltammetric charge assigned to HER reactions. It should be noted, however, that the minimum in the HER current is observed at a potential $E_{\mathrm{r}}^{\prime}$ slightly more positive than $E_{\mathrm{r}}$, that is, at a potential where $q_{\mathrm{Cu}}$ is close to that of the complete monolayer. $E_{\mathrm{r}}^{\prime}$ can probably be associated with the equilibrium potential of the $\mathrm{Cu}$ (monolayer)/Pt electrode. On the other hand, when the potential $E_{\mathrm{d}}$ is changed in the negative direction it appears that a slight excess of $\mathrm{Cu}$ atoms deposited on the complete $\mathrm{Cu}$ monolayer leads to cluster formation and the simultaneous appearance of bare $\mathrm{Pt}$ sites. These types of process are illustrated schematically in Fig. 9. This means therefore that at $E_{\mathrm{r}}$, clusters of bulk $\mathrm{Cu}$ as well as $\mathrm{Cu}$ adatoms are present on the electrode surface, and the rearrangement of the $\mathrm{Cu}$ overlayer results in the reappearance of bare $\mathrm{Pt}$ sites in the potential region of current peak $V_{a}$, as previously reported from voltammetric runs [11]. This conclusion is, in principle, also supported by the drastic change in the optical properties of the $\mathrm{Cu}$ electrodeposit as high degrees of surface coverage are reached [16].

The analysis of the current transients gives further confirmation of the previous conclusions. Thus, the monotonic current transients recorded for $E_{\mathrm{d}}$ values lying in the potential range of peaks $\mathrm{I}_{\mathrm{c}}, \mathrm{II}_{\mathrm{c}}$ and $\mathrm{III}_{\mathrm{c}}$ are characteristic of adsorption-desorption processes, as discussed elsewhere [17]. Conversely, as $E_{\mathrm{d}}$ approaches $E_{\mathrm{r}}$ by covering the potential range of peaks $\mathrm{IV}_{\mathrm{c}} / \mathrm{V}_{\mathrm{c}}$, the current transients exhibit a clear current plateau. The shape of these transients resembles those obtained for upd of 
880808080808080

$$
\downarrow \uparrow+30
$$

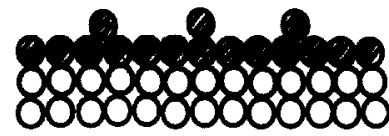

IN ITIATION

OF MULTILAYER
MONOLAYER

(2D)

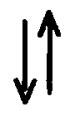

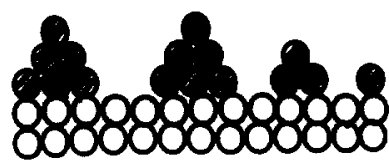

Fig. 9. Scheme of the possible processes at the atomic level leading from a $2 \mathrm{D}$ to a $3 \mathrm{D}$ structure at the early stages of a metal electrodeposit on a foreign substrate.

metals obeying the adsorption-desorption and nucleation and growth model [17]. This model requires the co-existence of two phases in the course of the electrochemical reaction, implying a randomly adsorbed phase and an ordered or condensed phase, the latter produced through the nucleation and growth process. This description is consistent with the simultaneous existence at $E_{\mathrm{r}}$ of $\mathrm{Cu}$ adatoms and clusters of bulk $\mathrm{Cu}$. According to this model, when $E_{\mathrm{d}}<E_{\mathrm{r}}$ the shape of the current transients resembles that predicted by nucleation and 3D growth mechanisms under diffusion [18]. In this case, for instantaneous nucleation, the current transient, $j(t)$, is given by the equation

$j(t)=\left(z F D^{1 / 2} c_{0} / \pi^{1 / 2} t^{1 / 2}\right)\left[1.0-\exp \left(-\pi k_{\mathrm{e}} D N_{0} t\right)\right]$

whereas for a progressive nucleation it is

$j(t)=\left(z F D^{1 / 2} c_{0} / \pi^{1 / 2} t^{1 / 2}\right)\left[1.0-\exp \left(-\pi k_{e}^{\prime} A D t^{2}\right)\right]$

where $D$ is the diffusion coefficient of the reacting species, $c_{0}$ is the bulk concentration of $\mathrm{Cu}^{2+}$ ions in solution, $k_{\mathrm{e}}$ and $k_{\mathrm{e}}^{\prime}$ are proportionality constants, $N_{0}$ is the number of sites available for nucleation and $A$ is the nucleation rate. For $t \rightarrow \infty$, eqns. (1) and (2) approach the following common expression:

$j(t)=z F D^{1 / 2} c_{0} / \pi^{1 / 2} t^{1 / 2}$

On the other hand, for $t \rightarrow 0$, eqn. (1) becomes

$j(t)={ }_{z} F D^{3 / 2} \pi^{1 / 2} c_{0} N_{0} k_{\mathrm{e}} t^{1 / 2}$ 


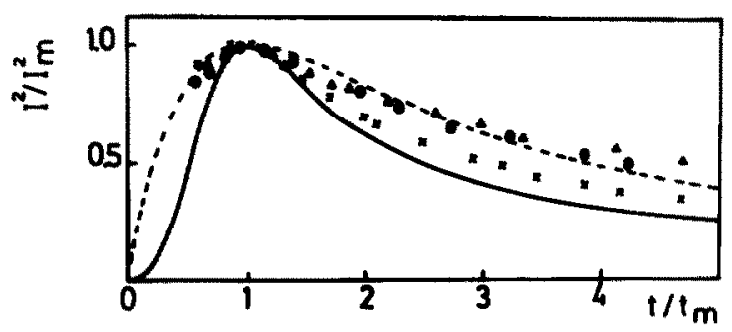

Fig. 10. Dimensionless plots of the current transients depicted in Fig. 8.

and eqn. (2) is reduced to

$j(t)=z F D^{3 / 2} \pi^{1 / 2} c_{0} A k_{\mathrm{e}}^{\prime} t^{3 / 2}$

Equation (3), which can be immediately verified by plotting $j$ vs. $t^{-1 / 2}$ for $t \rightarrow \infty$, is obeyed in the entire potential range of the present work. Unfortunately, it is more difficult to test the fulfilment of eqns. (4) and (5) because of the uncertainty in evaluating the initial decreasing current related to the absorption and electroformation of the first $\mathrm{Cu}$ monolayer. Nevertheless, this drawback can be circumvented by using dimensionless plots (Fig. 10). From these plots it can be concluded that bulk $\mathrm{Cu}$ deposition quite likely fulfils an instantaneous nucleation and growth mechanism in the entire time window, that is, including also the dependence of $j$ on $t^{-1 / 2}$ for $t \rightarrow \infty$ [18]. Values calculated from $j_{\mathrm{M}}$ and $t_{\mathrm{M}}$ are $N_{0}=1 \times 10^{6} / \mathrm{cm}^{2}$ and $D=(3 \pm 1) \times 10^{-6} \mathrm{~cm}^{2} / \mathrm{s}$.

The occurrence of the $2 \mathrm{D} \rightarrow 3 \mathrm{D}$ process in $\mathrm{Cu}$ electrodeposition offers a reasonable explanation for the HER current recorded under certain conditions in the voltammetric measurements. Thus, as $E_{\mathrm{d}}$ is made gradually more negative, the first monolayer of $\mathrm{Cu}$ begins to be formed under increasingly more drastic non-equilibrium conditions so that the nucleation and 3D growth process becomes more favourable. This process is accompanied by $\mathrm{H}$ adsorption at bare $\mathrm{Pt}$ sites. The number of these sites required for the initiation of the nucleation and growth process can be taken as equal to $N_{0}$, that is, $10^{6} / \mathrm{cm}^{2}$, a number which represents only a small fraction of the total number of Pt sites on the surface. But nucleation and 3D growth under diffusion control should imply the overlapping of diffusion lines instead of growing centres [18]. Therefore, this physical description of the early stages of $\mathrm{Cu}$ electrodeposition on $\mathrm{Pt}$ is coherent with the appearance of bare $\mathrm{Pt}$ sites in between randomly distributed $3 \mathrm{D}$ growth centres for $\mathrm{Cu}$. This conclusion agrees with X-ray fluorescence emission data for $\mathrm{Cu}$ electrodeposition on graphite electrodes indicating at $E_{\mathrm{d}}<E_{\mathrm{r}}$ clusters of several $\mu \mathrm{m}$ and bare electrode areas between the clusters at the early stage of the electrodeposition process [19].

\section{ACKNOWLEDGEMENTS}

This work was supported by the Consejo Nacional de Investigaciones Cientificas y Técnicas, the Comisión de Investigaciones Científicas de la Provincia de Buenos 
Aires. D.M. acknowledges the fellowship granted by the Deutscher Akademischer Austauschdienst, through the University of Mainz-University of La Plata Cooperation Agreement.

\section{REFERENCES}

1 G.W. Tindall and S. Bruckenstein, Anal. Chem., 40 (1968) 1051.

2 S.H. Cadle and S. Bruckenstein, Anal. Chem., 43 (1971) 932.

3 J.S. Hammond and W. Winograd, J. Electroanal. Chem., 80 (1977) 123.

4 D.M. Kolb, R. Kotz and K. Yamamoto, Surf. Sci., 87 (1979) 20.

5 C.L. Scortichini and C.N. Reilley, J. Electroanal. Chem., 152 (1983) 256.

6 S.M. Cadle and S. Bruckenstein, Anal. Chem., 44 (1972) 1993.

7 M.W. Breiter, Trans. Faraday Soc., 65 (1969) 2197.

8 D.M. Kolb in H. Gerischer and C.W. Tobias (Eds.), Advances in Electrochemistry and Electrochemical Engineering, Vol. 11, Wiley, New York, 1978, p. 125.

9 S. Stucki, J. Electroanal. Chem., 80 (1977) 375.

10 N. Furuya and S. Motoo, J. Electroanal. Chem., 72 (1976) 165.

11 W.J. Lorenz, E. Schmidt, G. Staikov and H. Bost, Faraday Symp. Chem. Soc., (1977) 15.

12 M.W. Breiter, J. Electrochem. Soc., 114 (1967) 129.

13 A.J. Arvia, J.C. Canullo, E. Custidiano, C.L. Perdriel and W.E. Triaca, Electrochim. Acta, 31 (1986) 1359.

14 R.C. Salvarezza, D.V. Vasquez Moll, M.C. Giordano and A.J. Arvia, J. Electroanal. Chem., 213 (1986) 301.

15 B.E. Conway, H. Angerstein-Kozlowska and W.A. Sharp, Anal. Chem., 45 (1973) 1331.

16 D.M. Kolb and R. Kötz, Surf. Sci., 64 (1977) 698.

17 E. Bosco and S.K. Rangarajan, J. Chem. Soc., Faraday Trans. 1, 77 (1981) 1673.

18 B. Scharifker and G.J. Hills, Electrochim. Acta, 28 (1983) 879.

19 B.H. Vassos and H.B. Mark, J. Electroanal. Chem., 13 (1967) 1. 